\title{
Algorithmic Trading Engines and Liquidity Contribution: The Blurring of "Traditional" Definitions
}

\author{
Sven S. Groth \\ Goethe University Frankfurt \& E-Finance Lab, Grüneburgplatz 1, \\ 60323 Frankfurt am Main, Germany \\ sgroth@wiwi.uni-frankfurt.de
}

\begin{abstract}
Being provided with a unique high-frequency dataset, we are able to show by means of an empirical analysis that computer-based traders, i.e. Algorithmic Trading (AT) engines, behave significantly different from human traders with regard to their order cancellation behaviour. Furthermore, given exactly this difference we point out that the application of well-established "traditional" liquidity measurement methods may no longer be unequivocally applicable in today's electronic markets. At least those liquidity measures that are based on committed liquidity need to be questioned.
\end{abstract}

Keywords: Liquidity provision, algorithmic trading, limit order book, option analogy.

\section{Introduction}

The evolution of electronic order books, such as Deutsche Börse's "Xetra" or London Stock Exchange's "SETS", eased the way for the automation of trading processes. Being able to access electronic markets via "Remote Access", the physical presence at an exchange is no longer necessary. Both brokers (sell side) and - at least - those institutional investors (buy side) that are provided with a direct market access are frequently making use of the "new" opportunities provided by electronic markets. One of the resulting success stories during the last decade deals with the proliferated utilization of so called "Algorithmic Trading" (AT) engines. Today the group of computer-based traders, i.e. AT, generate about one-half of trading activity on major European markets (e.g. Xetra) and the percentage share continues to grow [1].

In a broader sense, algorithmic trading can be defined as "the use of algorithms to manage the trading process" [2, p. 1]. In a narrower sense, it can be defined as "the automated, computer-based execution of equity orders via direct market-access channels, usually with the goal of meeting a particular benchmark" [3, p. 1]. Depending on the respective definition, the investment decision is either exogenous or endogenous to the AT model. If the original investment decision is exogenous to the AT model the task of an algorithm is "limited" to implement a given external trading intention with the goal to minimize market impact (implicit trading costs) and sustain potential alpha. This is the case when for example an investment fund manager makes a strategic investment decision that is large in volume. If this order is routed to the market as one 
big order, the potential market impact might jeopardize the investment yield aimed at. Therefore, these investment funds would advise brokers to, for instance, slice the original large order into several small orders. This task is conducted by both humans and AT engines with the difference that computers are usually cheaper to employ than humans. If the investment decision is endogenous to the AT model, the main goal of AT engines is not to sustain potential alpha, but to create alpha, i.e. find and implement profitable (intraday high frequency) investment strategies.

\section{Related Work and Derived Hypotheses}

Existing research on AT can be grouped into the categories algorithmic efficiency, algorithmic design / selection and algorithmic influence on the market. Literature on algorithmic efficiency aims to answer whether or not the use of algorithms, compared to traditional brokerage, creates additional value [3; 4]. Research on algorithmic design / selection guides especially practitioners on which kind of algorithm to choose for which kind of task and how to actually evaluate its' success [5;6]. The increased share of algorithmic trading activity during the last decade called for research on the algorithmic influence on the market as a whole. [7] sets up an agent-based simulation and evaluates the influence of AT on price formation and price volatility. [2] investigate whether or not AT improves liquidity and find that algorithmic trading and liquidity are positively related. But their proxy for AT, the normalized measure of "New York Stock Exchange" (NYSE) electronic message traffic, does not necessarily pick up variations in algorithmic liquidity supply though. Moreover, their approach is limited to the observation of a certain event and cannot be applied similarly in other markets. Consequently, having reviewed existing research on AT, we identified the liquidity contribution of AT as an area of research that still lacks sufficient insights.

This paper aims to fill this gap because - among other things - liquidity is an important determinant of market quality [8]. But instead of directly trying to identify relationships between AT activity and associated market liquidity as [2] did, we question whether or not existing liquidity measurement concepts are still applicable and most importantly - meaningful in today's electronic markets.

The cognition that "no single measure tells the whole story about liquidity" $[9, \mathrm{p}$. 55] has already been present for decades. Our main question, however, is whether or not the electronification of markets (including the increased utilization of AT engines) challenges existing, seemingly accepted, beliefs on the applicability of particular liquidity measures to certain market structures.

For example, the spread is one of the most commonly applied liquidity measures. A small difference between best bid and best ask usually indicates that a market is liquid. But as this liquidity measure is not capable to adequately capture all dimensions of liquidity (i.e. breadth, depth, immediacy, and resiliency), further liquidity measures such as the Cost of Round Trip (CRT) were proposed [10]. Hereby, CRT is defined as the weighted average price (VWAP) at which an order of a given size (D) can be executed. [10, p. 24] state that CRT will be "particularly useful in any market where a high proportion of available liquidity is committed [...][and] as world equity markets increasingly adopt a pure electronic order book architecture, the applications of CRT(D) should increase". The proposal of a similar approach by [11] underpins 
the increasing importance assigned to information contained in the depth of the order book. It may therefore be concluded that CRT is commonly viewed as an appropriate liquidity measure for today's electronic markets.

It is, however, questionable whether or not the majority of (visible) liquidity in today's electronic markets is in fact committed. For example, given their technical abilities, AT engines are able to constantly monitor the market and instantaneously react to market movements by adjusting / cancelling their orders. This expected behaviour lowers the probability of being executed against informed order flow. Thus, compared to human traders, AT engines provide / commit liquidity to the market for a shorter period of time. [12] support this hypothesis because they find that a large amount of (non-marketable) limit orders are cancelled within a very short period of time in a limit order market. They call these rapidly cancelled orders "fleeting orders" and because of their frequent appearance question the "usual framework of patient limit orders and impatient market orders" (p. 2). Hypothesis H1 is expressed accordingly and will be addressed by means of a survival analysis.

Hypothesis H1: The lifetime of AT orders is significantly shorter than the lifetime of Non-AT orders.

If the behaviour of AT engines is significantly different from humans (see for example H1; or [13]), if AT engines frequently make use of non-marketable - i.e. passive - limit orders, and if their market share is sufficiently large, the application of "traditional" liquidity measures that are based on the committed liquidity assumption may no longer be representative of overall market liquidity. Applying "traditional" liquidity measures to electronic markets with a large share of AT activity / trading might understate the liquidity contribution of this group of traders. This is especially true if AT engines commit liquidity only for a short period of time, but simultaneously represent a viable (passive) trading counterparty. In other words, even though AT engines do not commit liquidity to the market in a "traditional" sense these enhance a market's liquidity by increasing the probability of finding a (passive) trading counterparty. We therefore expect the "traditional" liquidity measures that are based on committed liquidity to be (systematically) significantly lower than an alternative trade-based liquidity measure. This, however, does not imply that the applied tradebased liquidity measure is superior to the other ones. It simply gauges a different aspect of liquidity provision that is not grasped by described "traditional" liquidity measures. Hence, Hypothesis $\mathrm{H} 2$ is expressed as follows:

Hypothesis H2: Liquidity measures that are based on committed liquidity exhibit significantly lower liquidity levels than alternative trade-based liquidity measures in markets with a high degree of AT activity.

As the evaluation of overall market liquidity alone does not allow us to evaluate Hypothesis $\mathrm{H} 2$, we will assess the liquidity contribution of AT engines. The main reason for this procedure is given by the fact that AT order flow is expected to be significantly different from Non-AT order flow (see H1).

Hypothesis $\mathrm{H} 2$ is addressed by means of an empirical analysis. In order to incorporate above identified time component into the liquidity assessment, we will adopt the well known and often cited limit order option analogy [14] as one liquidity measurement 
method. Similar to CRT, it also aggregates the state of the entire limit order book into a single number. Thereby, limit orders are viewed as free trading options. For example, a limit order on the bid side indicates that a trader is willing to buy shares at its limit price. Accordingly, other market participants are given the opportunity to sell shares to the limit order liquidity provider at the respective limit price. In this case, the liquidity provider writes a free put option, i.e. one that "gives the holder [i.e. other market participants] the right to sell the underlying asset [...] for a certain price [limit]" [15, p. 7]. In other words, a market is viewed as more liquid the more volume is available at the top of the order book and the longer the liquidity (i.e. limit orders) is provided to the market.

Finally, in order to discuss the usefulness / applicability of above liquidity measures, we provide the reader with a (liquidity) benchmark that is based on executed volume (by trader group). The benchmark builds upon the notion that markets may also be termed liquid, if a lot of trading activity occurs. The volume of trading or the number of transactions respectively also serve as input to the liquidity measures proposed by [16] and [17].

The remainder of the paper is organized as follows: First, we introduce the reader to a unique dataset that will allow us to scrutinize above hypotheses. Second, we will separately address above hypotheses by means of an empirical analysis. Third, we will discuss the usefulness of the measurement methods and possible implications for market microstructure, i.e. e-finance, research.

\section{Description of the Market and the Dataset}

\subsection{Xetra Trading System}

The Frankfurt Stock Exchange (FWB) is operated by Deutsche Börse AG and offers both floor trading and fully-electronic trading via Xetra. In terms of market share, in 2007, 98.30\% of order book turnover in German blue-chip DAX30 equities took place on Xetra. Remaining turnover was generated at FWB floor (1.08\%) and at other regional German exchanges (0.62\%) [1]. Dependent upon asset classes and corresponding asset liquidity, Xetra exhibits characteristics of a (1) pure order-driven, (2) pure quote-driven and (3) hybrid market model. Below analyses mainly concentrate on the pure-order driven market.

(1) Highly liquid shares, e.g. those included in the DAX30 index, do not need market makers to provide liquidity to the market. Instead, investors post orders into the limit order book. Equities are traded continuously between an opening and a closing call auction, interrupted by one (midday) intraday call auction. Additional intraday call auctions are triggered by so called volatility interruptions, i.e. whenever a potential execution price lies outside a pre-defined static and / or dynamic price range. Matching of orders follows the price-time priority rule.

(2) Xetra Best constitutes a functionality within the Xetra order book that allows for preferred execution of orders with order book consistency.

(3) Analogue to the pure order-driven market, the hybrid market allows for continuous trading interacting with auctions. Investors' orders are, however, complemented by limit orders (quotes) submitted by designated sponsors to improve liquidity. 


\subsection{Dataset}

Deutsche Börse AG provided us with high-frequency order book data for those companies that were member of the German blue-chip DAX30 index during the period under investigation, i.e. between 2007-10-08 and 2007-10-12. The dataset contains all Xetra order book events during continuous trading, (opening-, intraday-, and closing-) auctions, pre-trading, post-trading and volatility interruptions. Each order, which is assigned a unique order number by the trading system, should at least trigger two events: First, a submission event and second either a full execution or a cancellation / deletion event. Each order can be partially executed and / or modified more than once. In Xetra, a modification event merely refers to a reduction of order volume. An increase in order volume would negatively affect the priority or execution probability of other orders. In this case, the system automatically generates a deletion event for the modified order and a new order entry event with increased volume. Analogue, technical deletion and insertion events occur due to changing trade restrictions that do not affect the price-time priority of other orders.

For each event, if appropriate, the following additional information is provided: timestamp, ISIN (International Security Identification Number), order number, auction trade flag, order type, buy/sell indicator, (hidden) size, price / limit, event code, trade restriction, and ATflag. The auction trade flag indicates the trading phase, e.g. continuous trading, during which the specific event occurred. One order may reveal different auction trade flags as for example order submission and order execution can take place during different trading phases. Order type indicates whether an order is a limit order, market order, iceberg order or market-to-limit order. Orders may also be restricted to be exclusively executed during a certain trading phase (trade restriction), e.g. auctions.

The ATflag indicates whether $($ ATflag $=1)$ or not $($ ATflag $=0)$ a certain event has been triggered by an algorithm. It does not allow the identification and exploitation of activities of single market participants though. The identification of algorithms is made possible because Deutsche Börse AG offers its clients a special pricing model for computer generated trades (Automated Trading Program: AT). Participants of the Automated Trading Program oblige themselves to exclusively make use of the rebaterelevant AT User-ID whenever transactions have been generated by an electronic system. Thereby "the electronic system has to determine two out of the three following order parameters: price (order type and / or order limit where applicable), timing (time of order entry) and quantity (quantity of the order in number of securities). [...] The electronic system must generate buy or sell orders independently, i.e. without frequent manual intervention, using a specified program or data." [18, p. 1]. Considering both above "electronic system" definition and granted financial incentives (fee rebates), the AT flag can be appreciated as the best proxy for algorithmic trading activity currently available [19, p. 7]. It shall, however, be noted that despite of the strong financial incentives not all "algorithmic traders" may take part in the program.

The above dataset allows for an order book reconstruction of covered DAX30 securities at any time during the period under investigation, including all trading phases. Basically, all orders submitted prior to the time of interest, i.e. order book reconstruction, that are not fully executed, cancelled or deleted (including "deleted" invalid day orders) remain in the order book. The actual order limits are determined by further 
incorporating partial executions and modifications. The OrderEntryTimestamp allows for the consideration of time priority.

\section{Evaluation of Order Lifespan}

Hypothesis H1 is addressed by means of a survival analysis. Analogue to [12] we apply the life-table method. Thereby, for each order either "time to cancellation" (ttc) or "time to execution" (tte) are calculated. Results are broken down by levels of factor AT, i.e. has the order been submitted by an algorithm or not. Calculating the probability of cancellation, the execution event is used as (exogenous) censoring event, and vice versa. In this analysis, we merely refer to active cancellation. This does not include orders that are (automatically) deleted due to expiration. Actual (active cancellation) activities shall represent traders' behaviour best. The sample includes all non-marketable DAX30 limit orders without auction-only trade restrictions that were submitted during continuous trading (during the one week sample period). Results can be found in Table 1 .

Table 1. Cancellation and execution rates of limit orders

\begin{tabular}{|c|c|c|c|c|}
\hline \multirow[t]{3}{*}{ Time } & \multicolumn{4}{|c|}{ Cumulative proportion surviving at end of interval } \\
\hline & \multicolumn{2}{|c|}{ Cancellation } & \multicolumn{2}{|c|}{ Execution } \\
\hline & AT & Non-AT & AT & Non-AT \\
\hline 0.1 second $(\mathrm{s})$ & 0.877 & 0.958 & 0.986 & 0.991 \\
\hline 1 & 0.714 & 0.785 & 0.952 & 0.973 \\
\hline 2 & 0.662 & 0.729 & 0.941 & 0.967 \\
\hline 10 & 0.493 & 0.519 & 0.875 & 0.932 \\
\hline 1 minute(s) & 0.229 & 0.230 & 0.713 & 0.831 \\
\hline 2 & 0.148 & 0.137 & 0.633 & 0.773 \\
\hline 10 & 0.033 & 0.062 & 0.470 & 0.631 \\
\hline 1 hour & 0.001 & 0.004 & 0.148 & 0.145 \\
\hline $\begin{array}{l}\text { Wilcoxon (Ge- } \\
\text { han) statistic }\end{array}$ & \multicolumn{2}{|c|}{$15,174 * * *$} & \multicolumn{2}{|c|}{$56,429 * * *$} \\
\hline
\end{tabular}

Probability of cancellation during the first 100 milliseconds is $12.3 \%$ for AT orders and $4.2 \%$ for Non-AT orders. Significance values based on the Wilcoxon (Gehan) statistic, which is based upon the differences in group mean scores, provide evidence that the probabilities of cancellation are significantly different across groups AT and Non-AT. The same holds true for the probability of execution. To conclude, Hypothesis $\mathrm{H} 1$ can be corroborated as AT engines show a different cancellation behaviour than Non-AT traders, i.e. humans.

\section{Evaluation of Order Types}

In order to make valid predictions regarding Hypothesis H2, it first of all needs to be scrutinized whether or not AT engines frequently make use of non-marketable - i.e. 
passive - limit orders. If this is the case and if their market share is sufficiently large, the application of "traditional" liquidity measures that are based on the committed liquidity assumption are expected to be no longer representative of overall market liquidity. A descriptive summary of used order types can be found in Table 2. The respective sample consists of all orders from DAX30 companies without auction-only trade restrictions that were submitted during continuous trading (during the one week sample period).

Table 2. Order types

\begin{tabular}{llllll}
\hline Order type & \multicolumn{2}{l}{ No. of orders } & & \multicolumn{2}{c}{$\%$ of AT / Non-AT } \\
\cline { 2 - 3 } \cline { 5 - 6 } & AT & Non-AT & & AT & Non-AT \\
\hline Limit order & $2,163,801$ & $1,828,696$ & & $99.64 \%$ & $94.99 \%$ \\
$\quad(1)$ non-marketable & $1,911,213$ & $1,704,567$ & & $88.01 \%$ & $88.55 \%$ \\
$\quad(2)$ marketable & 252,588 & 124,129 & & $11.63 \%$ & $6.44 \%$ \\
Market order & 3,042 & 40,973 & & $0.14 \%$ & $2.13 \%$ \\
Iceberg order & 4,733 & 54,792 & & $0.22 \%$ & $2.85 \%$ \\
Market-to-Limit order & 0 & 599 & & $0.00 \%$ & $0.03 \%$ \\
SUM & $2,171,576$ & $1,925,060$ & & & \\
\hline
\end{tabular}

It can be observed that both groups of traders, i.e. AT and Non-AT, submit comparable number of orders. AT, however, make use of limit orders more frequently. $99.64 \%$ of all submitted AT orders are limit orders. This may be due to the fact that Non-AT deploy other order types such as iceberg orders $(2.13 \%)$ or market-to-limit orders $(2.85 \%)$ more often. It follows that the potential liquidity provision of algorithms via non-marketable limit orders is huge. $52.86 \%$ of all non-marketable limit orders are submitted by algorithms. For a discussion on why limit order trading actually seems viable see for instance [20].

It shall be noted that the average size of AT orders is smaller than the average size of Non-AT orders (not shown here). Systematically smaller AT order sizes may in fact lower the absolute value of below described committed liquidity contribution measures. The relative comparison to the trade-based liquidity measure is, however, not influenced by lower order sizes.

\section{Evaluation of Liquidity Measures}

In order to address Hypothesis H2, we introduce three different liquidity measures and apply them to the dataset. Potentially differing results will then serve as a basis to discuss the usefulness of each liquidity measure, especially with regard to the application in markets with a large degree of AT activity. The first two liquidity measures will stick to the "traditional" notion and will basically concentrate on the amount of limit orders in the order book. For both calculations, the order book is reconstructed on a minute-by-minute basis and the two liquidity measures are calculated according to below description. The third liquidity measure, however, is totally different in nature. It defines liquidity by means of trading activity. 


\subsection{Pure Order Volume}

The first measure of AT liquidity contribution via non-marketable limit orders is a quite simple one. For each (minute-by-minute) reconstructed limit order book, we know which order has been submitted by an algorithm, i.e. member of the AT-program, or a human trader (see Table 3, AT orders are marked grey). Liquidity contribution by AT engines is then defined as the share of pure submitted volume resting in the order book ( $\sum \mathrm{AT}$ size $/ \sum$ size $) .{ }^{1}$ It follows that this liquidity measure is based on committed liquidity, i.e. liquidity provided to the market via non-marketable limit orders.

Table 3. Exemplary order book

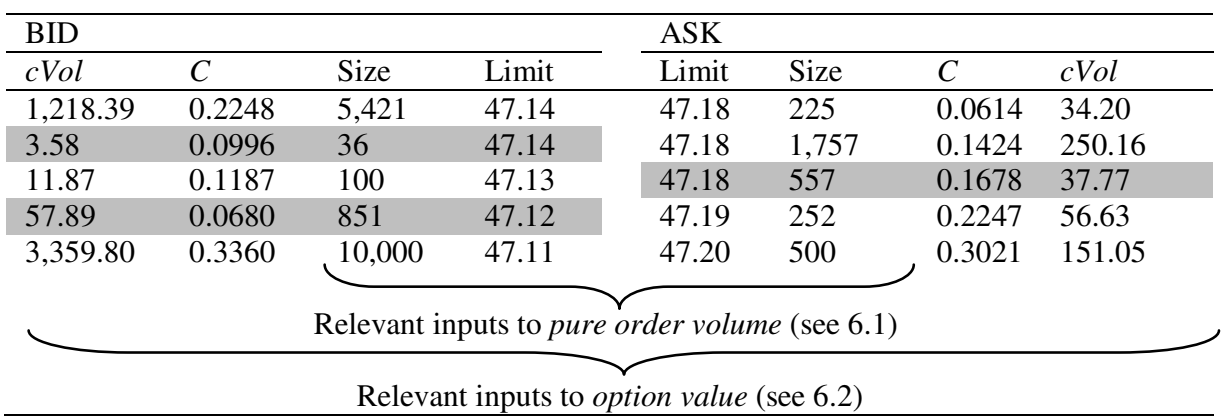

\subsection{Option Value}

The volume measure takes account of the depth of the order book, but obviously does not differentiate between order aggressiveness and the time of liquidity contribution. In order to incorporate these dimensions as well and, especially, to show the impact of above identified lifespan differences (Hypothesis H1), above introduced limit order option analogy is applied by means of the order book option value. [14, p. 1457] were the first to empirically evaluate the option-like characteristics of limit orders "by characterizing the cost of supplying quotes, as writing a put and a call option ['free' straddle option] to an information-motivated trader". Since then the approach has been applied to both non-dealer markets such as the Australian Stock Exchange [21] and hybrid markets such as the New York Stock Exchange [22].

Based on the Black \& Scholes [23] option pricing model (see Formula 1, 2, 3 for a call option), option values are calculated for all limit orders in the order book (also see Table 3). These limit order option values $C$ are multiplied with their respective volumes to achieve $c$ Vol. Afterwards, aggregate option values ( $\sum \mathrm{cVol}$ ) for both the bid and the ask side are calculated, including (1) all limit orders and (2) only ATorders. Respective values for the whole order book $(c A l l)$ are achieved by equally

${ }^{1}$ Example BID side (given that the displayed orders constitute the whole order book): " $\sum$ AT size" is equivalent to the sum of those orders that are marked grey, i.e. $36+851=887$. " $\sum$ size" is the sum of all orders resting in the order book, i.e. 16,408. The AT liquidity contribution for this particular point in time is then 0.054 . 
weighting AT liquidity contribution of the bid and the ask side. Inputs to the option pricing model were chosen as described below.

$$
\begin{gathered}
C_{0}=S_{0} N\left(d_{1}\right)-X e^{-r T} N\left(d_{2}\right) \\
d_{1}=\frac{\ln \left(\frac{S_{0}}{X}\right)+\left(r+\frac{\sigma^{2}}{2}\right) T}{\sigma \sqrt{T}} \\
d_{2}=d_{1}-\sigma \sqrt{T}
\end{gathered}
$$

$C_{0} \quad$ Current call option value

$S_{0} \quad$ Current stock price

$N(d) \quad$ Probability that a random draw from a standard normal distribution will be less than $d$.

X Exercise price

$r \quad$ Risk-free interest rate

T Time to maturity

$\Sigma \quad$ Standard deviation

\subsubsection{Asset Price and Strike Price $\left(S_{0}, X\right)$}

Following the option analogy, asset price $S$ is given by the security's mid-point. Strike price $X$ is the price of the limit order. Options are always out-of-the-money. In the case of bid put options, the asset price is larger than the strike price $(S>X)$, and in the case of ask call options, the asset price is smaller than the strike price $(S<X)$.

\subsubsection{Riskless Rate of Interest $(r)$}

We use the 3-month EURIBOR (Euro Interbank Offered Rate) as of 2007-10-08 for the risk-free interest rate. Analogue to [22, p. 37] we believe that "the assumed interest rate has essentially no impact on the results since the short time intervals [option's maturity] involved ensure that it has little effect on the option values". Moreover, any bias will likely affect both sides of the order book and both AT and Non-AT orders. The riskless rate of return as well as the following figures "volatility" and "maturity" were annualized.

\subsubsection{Asset's Volatility $(\sigma)$}

[21] calculate implied standard deviations using the method proposed by [24]. [22] estimate volatility by its annualized daily return variance and mention that a timevarying volatility model was not expected to change their results. We follow their approach and estimate end-of day volatilities. Daily closing data is directly taken from "Reuters Tick History" (University access) for the six month period prior to the observation period.

\subsubsection{Option's Maturity $(T)$}

The life of a limit order begins upon submission and ends upon full execution, cancellation or expiration (deletion). [21] arbitrarily allocate lifetimes to the limit orders. Thereby, all limit orders independent of their size or position in the order book are treated alike and are expected to remain in the order book for the same amount of 
time. In contrast, [22] model limit order lifetimes depending on their prices, sizes and market conditions. We also believe that the expected lifetime of orders is dependent upon both individual order particularities and the order book situation. Therefore, for each security the following linear model is estimated:

$$
\begin{gathered}
\text { E(logTtr })=\beta_{0}+\beta_{1} \log \text { Age }+\beta_{2} \text { queue }+\beta_{3} \text { middiff }+\beta_{4} \text { logTimetoClose } \\
+\beta_{5} \text { dummytoday }+\beta_{6} \text { size }+\beta_{7} \text { ATflag }+\beta_{8} \text { queue } \\
* \text { TimetoClose }+\beta_{9} \text { middiff } * \text { TimeToClose }
\end{gathered}
$$

The estimated "time to removal" (Ttr) includes execution, cancellation and expiration events. Analogue to [22], we log the dependent variable Ttr to control for residual heteroskedasticity. LogAge refers to the (log) time the respective order has already rested in the order book. Qиеие represents the cumulated volume (size) of orders with higher price priority and time precedence. Before the respective order can be executed, all orders in the quеие need to be executed (or cancelled) first. Middiff is the absolute difference between the orders limit and the mid-point between best bid and best ask. TimetoClose is the (log) minute time until the end of the trading day. Dummytoday constitutes a dummy variable that indicates whether (1) or not (0) an order was submitted the same day. Size naturally refers to the submitted volume of the respective order. In our case, it includes both visible size and hidden size provided by iceberg orders. Finally, the ATflag indicates whether (1) or not (0) the respective order was submitted by an algorithm. Analogue to [22], the two interaction terms model cross-effects among terms quеие and TimetoClose and among terms middiff and TimetoClose.

For the estimation samples, the order book is reconstructed on a minute-by-minute basis each trading day between 9:00 AM and 5:30 PM. Then logTtr is estimated for all (limit) orders in the order book where the time of removal is known. Given the minute-by-minute order book reconstruction approach, the same orders may appear in different estimation samples at different times with different inputs though.

Regression results can be found in Table 4. Analogue to below analyses, calculations are conducted on a sub-sample of five randomly chosen DAX30 companies. Except on the coefficient queue (ALV), all coefficients are significant at the $1 \%$-level. It can be observed that AT orders have a shorter lifetime than Non-AT orders, i.e. (negative coefficient). It shall, however, be noted that Ttr is influenced by both execution and cancellation events that may act in different directions. For example, regarding middiff it might be expected that more aggressively priced orders are executed earlier. This is due to the fact that these rest at the top of the order book. Simultaneously, less aggressively priced orders are presumed to be cancelled more frequently. Less aggressively priced orders, waiting deep in the order book, are less likely to be executed and due to new information arrival might need to be updated. The observation of negative coefficients for middiff therefore provides evidence that the "cancellation-effect" outweighs the "execution-effect". Comparatively low fill rates (not shown here in detail), i.e. the percentage of orders that were actually executed, of $11.78 \%$ for Non-AT submitted orders and $17.12 \%$ for AT submitted orders confirm the importance of the "cancellation-effect". 
Table 4. Regression coefficients from linear model

\begin{tabular}{llllll}
\hline Company*: & ALV & BMW & DTE & MAN & CON \\
\hline Adjusted R ${ }^{2}$ & 0.553 & 0.520 & 0.513 & 0.595 & 0.609 \\
Constant & -0.4203 & -0.1116 & 0.2383 & -1.4575 & -0.6203 \\
logAge & 0.6263 & 0.5063 & 0.4935 & 0.6423 & 0.5848 \\
Queue & $1.4 \mathrm{E}-06$ & $1.8 \mathrm{E}-06$ & $6.0 \mathrm{E}-08$ & $4.9 \mathrm{E}-06$ & $5.2 \mathrm{E}-06$ \\
Middiff & -0.0003 & -0.0155 & -0.0031 & 0.0022 & -0.0041 \\
logTimetoClose & 0.3447 & 0.3919 & 0.3834 & 0.5213 & 0.4065 \\
dummytoday & 0.3517 & 0.2310 & 0.0603 & 0.4421 & 0.2944 \\
Size & $-1.4 \mathrm{E}-05$ & $-1.2 \mathrm{E}-05$ & $-6.8 \mathrm{E}-06$ & $-3.7 \mathrm{E}-05$ & $-6.5 \mathrm{E}-05$ \\
ATflag & -0.3631 & -0.3966 & -0.3476 & -0.2081 & -0.3663 \\
QueueTimetoClose & $6.6 \mathrm{E}-11$ & $2.6 \mathrm{E}-11$ & $7.5 \mathrm{E}-12$ & $2.3 \mathrm{E} 11$ & $1.7 \mathrm{E}-10$ \\
middiffTimetoClose & $-1.8 \mathrm{E}-07$ & $-1.1 \mathrm{E}-06$ & $-1.0 \mathrm{E}-07$ & $-7.7 \mathrm{E}-08$ & $-5.5 \mathrm{E}-08$ \\
\hline
\end{tabular}

* ALV = Allianz; BMW; DTE $=$ Deutsche Telekom; MAN; CON = Continental

\subsection{Passive Trading Counterparty}

The last proposed measure evaluates the liquidity of a market by means of trading activity. The liquidity measure is assumed to be especially useful for the assessment of markets where the majority of liquidity is not "committed", but a lot of trading activity occurs. Analogue to previous liquidity measures, the main focus is again laid on those (limit) orders that seemingly provide liquidity by passively sitting in the order book. Looking at actual executions, it is assessed how much volume is executed against passive AT limit orders. In other words, this measure builds upon the notion that a market is more liquid, the higher the probability of finding a "passive" trading counterparty is. This definition, of course, merely refers to the liquidity contribution of AT engines.

\subsection{Results}

Results for the first two liquidity measures pure order volume and option value can be found in Table 5. Regarding the first two liquidity contribution figures, two findings are obvious:

First, the liquidity contribution of AT engines suggested by pure submitted volume is consistently larger than the value suggested by option valuation. The most likely reason for this finding may be found with the "time of liquidity contribution" (see Table 1, Table 4). Consequently the free trading option offered to the market is less valuable.

Second, the values provided by both methods are much smaller than the share assumed by the number of non-marketable limit orders submitted by AT engines. In the whole DAX30 sample, 54.20\% of all submitted limit orders originate from algorithms. Thereby, $88.01 \%(1,911,213)$ of all AT-submitted orders are non-marketable limit orders (see Table 2). 
Table 5. AT liquidity contribution

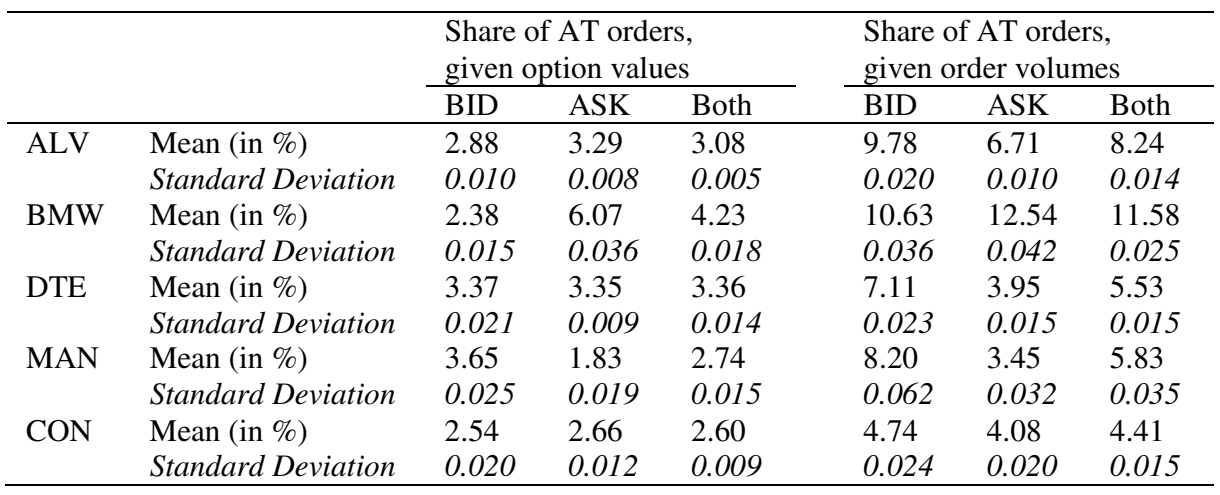

Results for the third liquidity measure passive trading counterparty can be found in Table 6. The figure of interest is the one where AT engines constitute the passive counterparty within a trade. In other words, the passive limit orders sit in the order book and are executed because of an incoming market order or marketable limit order. The share of AT being Non-Aggressor is comparatively high. For example, $40.28 \%$ of executed volume in BMW is executed against passive AT engines.

Table 6. Volume of executions with AT as Non-Aggressor

\begin{tabular}{lllllll}
\hline & $\begin{array}{l}\text { Volume of } \\
\text { executions }\end{array}$ & Aggressor & & & \multicolumn{2}{l}{$\begin{array}{l}\text { Non-Aggressor } \\
\text { (passive counterparty) }\end{array}$} \\
\cline { 3 - 4 } \cline { 6 - 7 } & & AT & Non-AT & & AT & Non-AT \\
\hline ALV & $9,129,140$ & $54.83 \%$ & $45.17 \%$ & & $42.97 \%$ & $57.03 \%$ \\
BMW & $10,760,588$ & $46.85 \%$ & $53.15 \%$ & & $40.28 \%$ & $59.72 \%$ \\
DTE & $111,047,806$ & $34.18 \%$ & $65.82 \%$ & & $32.34 \%$ & $67.66 \%$ \\
MAN & $6,811,806$ & $39.52 \%$ & $60.48 \%$ & & $36.65 \%$ & $63.35 \%$ \\
CON & $5,176,324$ & $39.66 \%$ & $60.34 \%$ & & $38.67 \%$ & $61.33 \%$ \\
\hline
\end{tabular}

Even though both the last liquidity measure passive trading counterparty and the first two liquidity measures order volume and option value incorporate passive nonmarketable limit orders submitted by AT, the results significantly ${ }^{2}$ differ from each other. This is due to the fact that AT engines behave significantly different from humans (Hypothesis H1) and that this behaviour cannot sufficiently be grasped by "traditional" liquidity measures. For example, the option value approach implicitly assumes that

${ }^{2}$ Liquidity measures order volume and option value were calculated on a minute-by-minute basis given the reconstructed order books. Based on a simple t-test it can be concluded that these two figures statistically significantly differ from each other. Figures of the liquidity measure passive trading counterparty are based on the calculation of the one-minute period prior to the respective order book reconstruction. Based on two t-tests, this measure also statistically significantly differs from the other two measures. Pre-requisites for the t-test are fulfilled. 
those orders which seemingly provide liquidity to the market by non-marketable limit orders are also the ones that will finally be executed. But especially for the new trader group, AT engines, this is not necessarily true: AT engines place their limit orders in such a way that these will remain in the order book for only a short period of time which results in a low option value. These might not want to reveal their trading intentions to the market by means of providing free trading options. Analogue to above liquidity definition, this part of liquidity is merely "committed" for a very short period of time. Nonetheless, proven by the volume of executions (Table 6), these do provide (passive) liquidity to the market. This liquidity, however, is merely transient / fleeting and may only reveal itself when an eligible trading counterparty emerges. To conclude, Hypothesis $\mathrm{H} 2$ can be corroborated.

\section{Conclusion}

Having conducted a short literature review on AT, we identified the interaction of algorithmic trading (i.e. technology) and liquidity as an important area of research that still lacks rigorous insights and methodologies. Pursuing to fill this gap, we assess the applicability of liquidity measurement concepts in the presence of frequent AT activity. As liquidity measures, such as the order book option value, are to a certain degree based on a particular market (behaviour) belief, the derived results also provide evidence how AT order flow blurs traditional definitions.

Being provided with a unique high frequency dataset that enables us to allocate the origin of each single order in the order book to either "algorithms" or "normal" human traders, we are - to our knowledge - the first to draw valid conclusions on the liquidity contribution of AT engines. To summarize, the empirical analysis provides evidence that AT engines behave significantly different from human traders with regard to their order cancellation behaviour. Furthermore, given exactly these differences, we were able to show that the application of liquidity measures that are based on "traditional" (liquidity commitment) market microstructure beliefs do not necessarily represent the "real" liquidity contribution of AT engines. Due to the fact that the share of AT trading is likely to increase in European markets, the potential for liquidity misinterpretation might even increase and should therefore be taken into account by traders, market providers, and researchers. Nonetheless, it shall be noted that we do not want promote the "one" right liquidity measure, but instead we hope to trigger a discussion on the usefulness of certain liquidity measures in today's electronic markets. Overall, we were able to show that the heavy use of technology (i.e. AT engines, computers) changes the way financial markets work and therefore also the way these should be assessed / interpreted.

Future work will include above appraisal on the whole DAX30 dataset. Moreover, the relation between different liquidity measures over a period of time will be investigated. The assessment of intraday patters might also provide an interesting direction of future research.

\section{Acknowledgments}

The author gratefully acknowledges the support of the E-Finance Lab, Frankfurt for this work. 


\section{References}

1. Deutsche Börse AG: Factbook 2007 (2007), http: / / deutsche-boerse.com

2. Hendershott, T., Jones, C., Menkveld, A.: Does Algorithmic Trading Improve Liquidity? WFA Paper 2008 (2008), http: / / ssrn. com/abstract $=1100635$

3. Domowitz, I., Yegerman, H.: The Cost of Algorithmic Trading - A First Look at Comparative Performance. In: Bruce, B. (ed.) Algorithmic Trading: Precision, Control, Execution, pp. 30-40. Institutional Investors Inc. (2005)

4. Chakravarty, S., Kalev, P., Pham, L.T.: Stealth Trading in Volatile Markets. Working Paper, Monash University, Australia (2005)

5. Yang, J., Jiu, B.: Algorithm Selection: A Quantitative Approach. In: Algorithmic Trading II, pp. 26-34. Institutional Investor, New York (2006)

6. Kissel, R., Malamut, R.: Algorithmic Decision-Making Framework. Journal of Trading 1, 12-21 (2006)

7. Gsell, M.: Assessing the Impact of Algorithmic Trading on Markets: A Simulation Approach. In: Proceedings of the 16th European Conference on Information Systems (ECIS), pp. 587-598 (2008)

8. Gomber, P., Schweickert, U., Theissen, E.: Zooming in on Liquidity. In: 9th Symposium on Finance, Banking and Insurance (2004)

9. Bernstein, P.L.: Liquidity, Stock Markets, and Market Makers. Financial Management 16(2), 54-62 (1987)

10. Irvine, P., Benston, G., Kandel, E.: Liquidity beyond the Inside Spread: Measuring and Using Information in the Limit Order Book. Working Paper, Emory University \& Hebrew University (2000)

11. Barclay, M., Christie, W.: Effects of Market Reform on the Trading Costs and Depths of Nasdaq Stocks. Journal of Finance 54, 1-34 (1999)

12. Hasbrouck, J., Saar, G.: Technology and Liquidity Provision: The Blurring of Traditional Definitions. Journal of Financial Markets (2008)

13. Gsell, M., Gomber, P.: Algorithmic Trading Engines Versus Human Traders - Do They Behave Different in Securities Markets? In: Proceedings of the 17th European Conference on Information Systems, ECIS (2009)

14. Copeland, T.E., Galai, D.: Information Effects on the Bid-Ask Spread. Journal of Finance 38(5), 1457-1469 (1983)

15. Hull, J.: Options, Futures, and Other Derivative Securities, 2nd edn. Prentice Hall, Englewood Cliffs (1993)

16. Cooper, S.K., Groth, J.C., Avera, W.E.: Liquidity, Exchange Listing, and Common Stock Performance. Journal of Economics and Business, 21-33 (1985)

17. Marsh, T., Rock, K.: Exchange Listing and Liquidity: A Comparison of the American Stock Exchange with the NASDAQ National Market System. American Stock Exchange Transactions Data Research Project No. 2 (1986)

18. Deutsche Börse AG: ATP Agreement for Participation in the "Automated Trading Program" (ATP) via the Electronic Trading System Xetra, http://deutscheboerse.com

19. Deutsche Börse AG: Xetra: International führende Plafform für den Börsenhandel - Hohe Geschwindigkeit, geringe Latenz, http: / / deut sche-boerse.com

20. Handa, P., Schwartz, R.A.: How Best to Supply Liquidity to a Securities Market - Investors want three Things from the Markets: Liquidity, Liquidity, and Liquidity. The Journal of Portfolio Management, 44-51 (1996) 
21. Jarnecic, E., McInish, T., Zürich, T.H.: An Empirical Investigation of the Option Value of the Limit Order Book on the Australian Stock Exchange. In: Financial Management Association International Conference (1997)

22. Harris, L.E., Lawrence, E., Panchapagesan, V.: The Information Content of the Limit Order Book: Evidence from NYSE Specialist Trading Decisions. Journal of Financial Markets 8(1), 25-67 (2005)

23. Black, F., Scholes, M.: The Pricing of Options and Corporate Liabilities. Journal of Political Economy 81 (1973)

24. Brenner, M., Subrahmanyam, M.G.: A Simple Formula to Compute the Implied Standard Deviation. Financial Analysts Journal, 80-83 (1988) 